\section{Signet-ring cell carcinoma of the appendix: a case report with an emphasis on sonographic findings}

\author{
Young Jong Cho' ${ }^{1}$, Hyuk Jung Kim¹, Suk Ki Jang ${ }^{1}$, Jae Woo Yeon ${ }^{1}$, Ki Ho Kim², So Ya Paik ${ }^{3}$ \\ Departments of ${ }^{1}$ Radiology, ${ }^{2}$ Surgery, and ${ }^{3}$ Diagnostic Pathology, Daejin Medical Center, \\ Bundang Jesaeng General Hospital, Seongnam, Korea
}

In this report, we present a rare case of primary signet-ring cell carcinoma of the appendix in a 51 -year-old woman with right lower quadrant pain. Since non-specific concentric appendiceal wall thickening was found in a radiologic evaluation, it was misdiagnosed as nontumorous appendicitis. An in-depth examination of the correlation between sonographic and histopathologic findings demonstrated that a single markedly thickened hypoechoic layer was well correlated with the diffuse infiltration of tumor cells in both the submucosal and muscle layers. If this sonographic finding is observed in certain clinical settings, such as potential ovarian and peritoneal metastasis, submucosal infiltrative tumors, including signet-ring cell carcinoma, should be considered in the differential diagnosis.

Keywords: Carcinoma, signet ring cell; Ultrasonography; Appendix

\section{Introduction}

Primary neoplasms of the appendix constitute approximately $0.5 \%-1.0 \%$ of appendectomy specimens upon pathologic evaluation [1-3]. Signet-ring cell carcinoma of the appendix is extremely rare, comprising only $4 \%$ of all primary appendiceal neoplasms [4]. It is often misdiagnosed because patients with an appendiceal tumor present with signs and symptoms suggestive of acute nontumorous appendicitis [1].

Primary signet-ring cell carcinoma of the appendix is a clinically aggressive type of cancer that often spreads to the pelvic lymph nodes, ovaries, and peritoneal surfaces by the time of diagnosis [3-8]. Therefore, preoperative detection of this type of cancer is essential for determining the extent and approach of surgery. However, its diagnosis is always challenging because its radiologic features are undefined $[4,5,7,8]$. To our knowledge, few cases have been reported in the literature, and previous reports have only described non-specific computed tomography (CT) and ultrasonography (US) findings similar to non-tumorous appendicitis, without evaluating the histopathologic correlations of the imaging findings $[4,5,7,8]$. In this case report, we describe the US findings of primary signet-ring cell carcinoma of the appendix in relation to the tumor's histopathological characteristics.

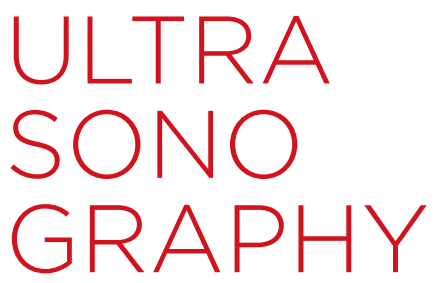

\section{CASE REPORT}

http://dx.doi.org/10.14366/usg.15063 pISSN: 2288-5919 - elSSN: 2288-5943 Ultrasonography 2016;35:164-167

Received: October 3, 2015

Revised: November 23, 2015

Accepted: November 24, 2015

Correspondence to:

Hyuk Jung Kim, MD, Department of

Radiology, Daejin Medical Center,

Bundang Jesaeng General Hospital, 20

Seohyeon-ro 180 beon-gil, Bundang-

gu, Seongnam 13590, Korea

Tel. +82-31-779-0051

Fax. +82-31-779-0062

E-mail: hyukjungk@naver.com

This is an Open Access article distributed under the terms of the Creative Commons Attribution NonCommercial License (http://creativecommons.org/ licenses/by-nc/3.0/) which permits unrestricted noncommercial use, distribution, and reproduction in any medium, provided the original work is properly cited.

Copyright (C) 2016 Korean Society of Ultrasound in Medicine (KSUM)

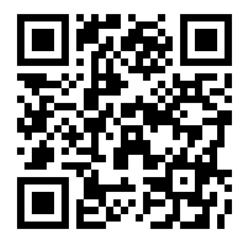

How to cite this article:

Cho YJ, Kim HJ, Jang SK, Yeon JW, Kim KH, Paik SY. Signet-ring cell carcinoma of the appendix: a case report with an emphasis on sonographic findings. Ultrasonography. 2016 Apr;35(2):164-167. 


\section{Case Report}

A 51-year-old woman came to our emergency room complaining of pain in the right lower quadrant that had begun the day before. During her physical examination, right lower quadrant tenderness and rebound tenderness were noted. A full blood count was within normal parameters except for a mild elevation of C-reactive protein to approximately $1 \mathrm{mg} / \mathrm{dL}$. US was performed with the clinical suspicion of acute appendicitis.

US revealed a diffusely and markedly thickened appendix measuring approximately $15 \mathrm{~mm}$. US-guided tenderness was positive in the right lower quadrant of the abdomen. These findings were consistent with acute appendicitis. However, several US findings were peculiar in comparison with typical non-tumorous appendicitis. First, the true luminal diameter was smaller than is typically observed in acute appendicitis. Instead, circumferential wall thickening was a prominent feature. Second, the submucosal and muscle layers were markedly hypoechoic and wall stratification was lost. Third, appendiceal wall thickening was more noticeable than periappendiceal fatty infiltration (Fig. 1A). In addition, a soft-tissue mass-like lesion approximately $4 \mathrm{~cm}$ in size with a heterogeneous echotexture was observed in the right adnexa (Fig. 1B).

Abdominopelvic CT was performed for further evaluation of the appendix and the ovarian soft-tissue mass. It showed an enhanced, thickened appendiceal wall with mild periappendiceal fatty infiltrations (Fig. 1C). These CT findings were indistinguishable from those usually associated with acute non-tumorous appendicitis. The presence of a 4-cm enhancing ovarian soft-tissue mass was also confirmed (Fig. 1D).

The patient underwent an appendectomy and right-sided salpingo-oophorectomy since acute appendicitis and an ovarian neoplasm were suspected. Upon pathologic examination, the appendiceal wall was observed to be asymmetrically thickened by the infiltration of signet-ring cells (Fig. 1E, F). Vascular, neural, and meso-appendiceal invasions were also noticed, and the ovarian mass was determined to be a metastatic lesion. After the diagnosis was confirmed, the patient underwent right hemicolectomy at a tertiary teaching hospital upon the patient's request.

\section{Discussion}

Primary appendiceal neoplasms are uncommon, with a reported prevalence of $0.5 \%-1 \%$ after appendectomies [1-3]. Data from our hospital are similar, with $0.9 \%$ (80 cases) reported in 9,227 appendectomy specimens over the past 14 years. Primary signetring cell carcinoma of appendix is even rarer, comprising $4 \%$ of all primary appendiceal neoplasms [4]. In our institute, only one case out of 80 primary appendiceal neoplasms was confirmed to be primary signet-ring cell carcinoma of the appendix.

Approximately $30 \%-50 \%$ of patients with primary neoplasms of the appendix, including signet-ring cell carcinoma, present with clinical symptoms that are indistinguishable from those of acute

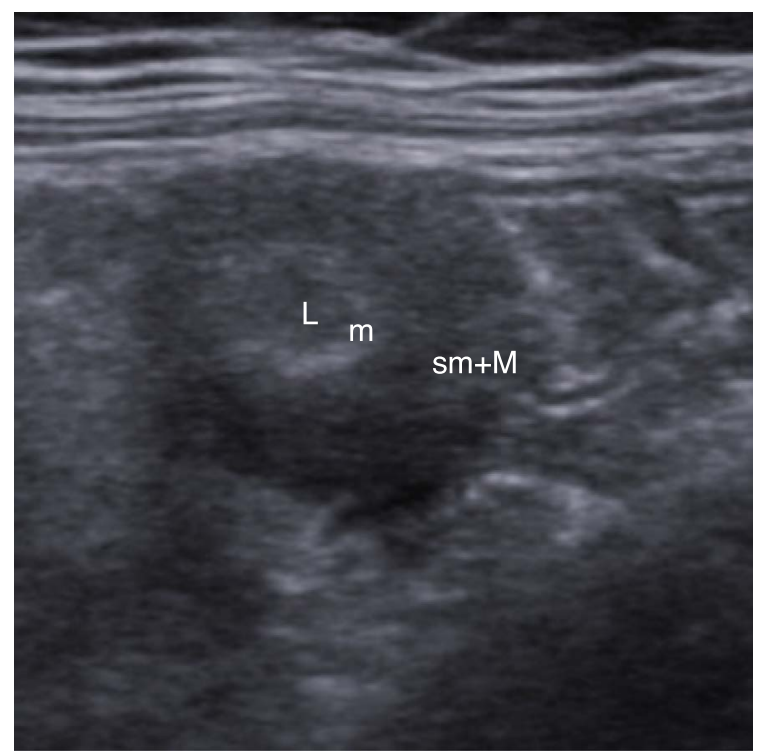

A

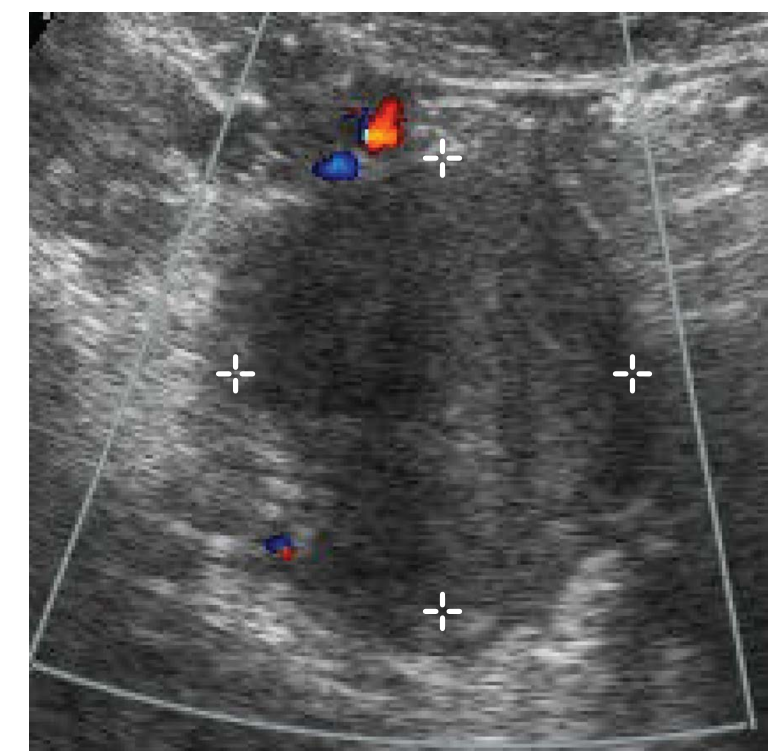

B

Fig. 1. A 51-year-old woman with right lower quadrant pain.

A. An axial sonogram image of the appendix shows a concentrically thickened wall with marked hypoechoic submucosal and muscle layers that are not clearly distinguishable. B. In a color Doppler examination, a well-demarcated heterogeneous echoic solid mass with a weak flow signal, approximately $4 \mathrm{~cm}$ in size, was found. 


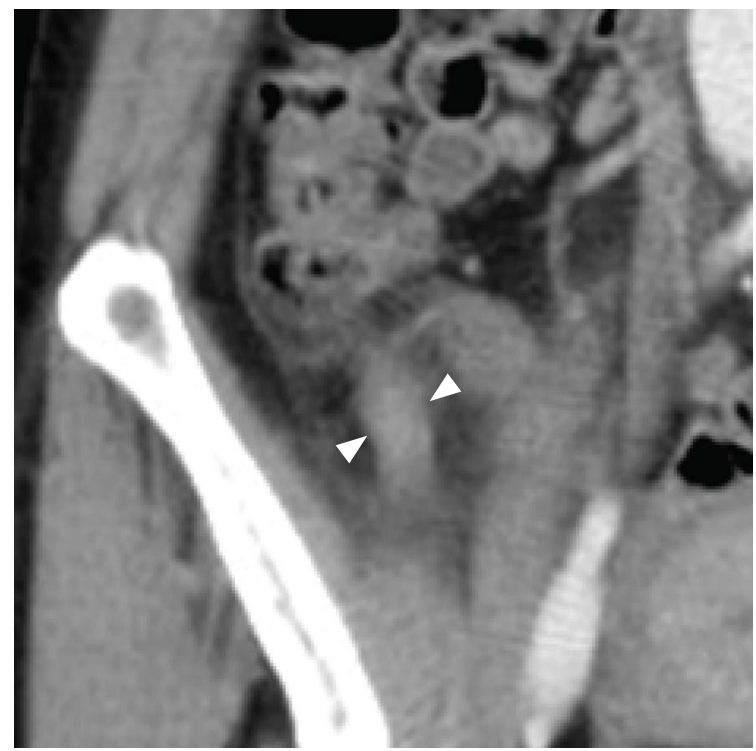

C

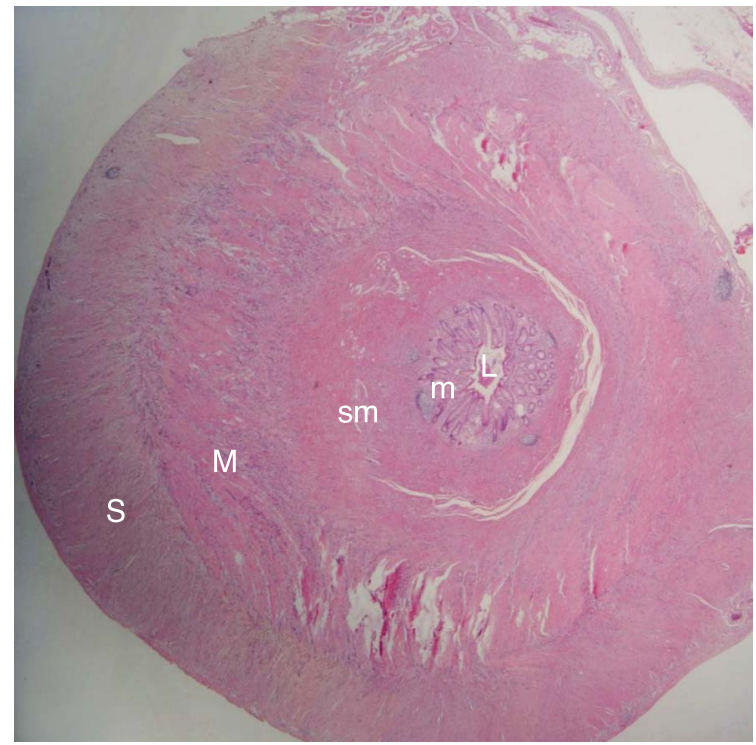

$\mathrm{E}$

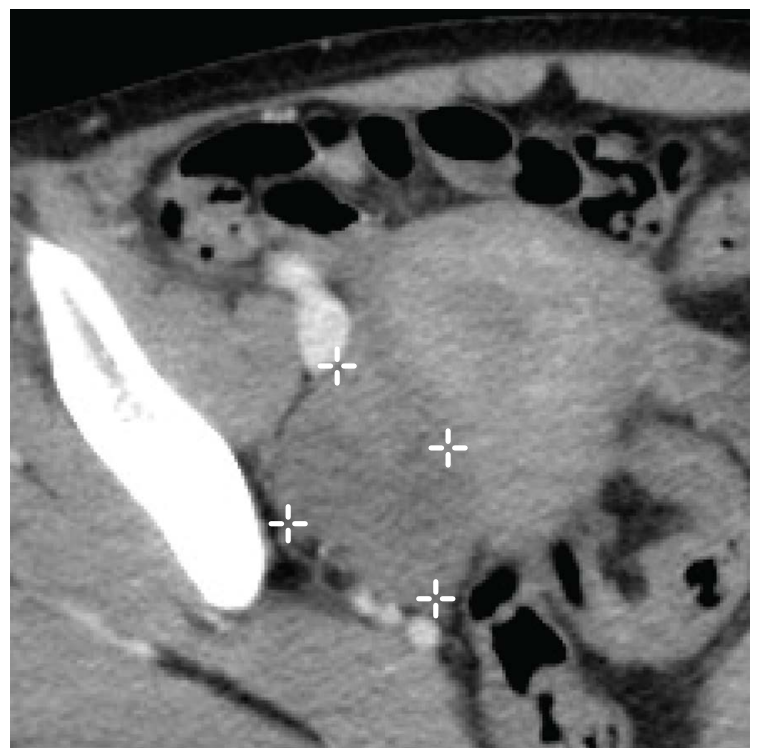

D

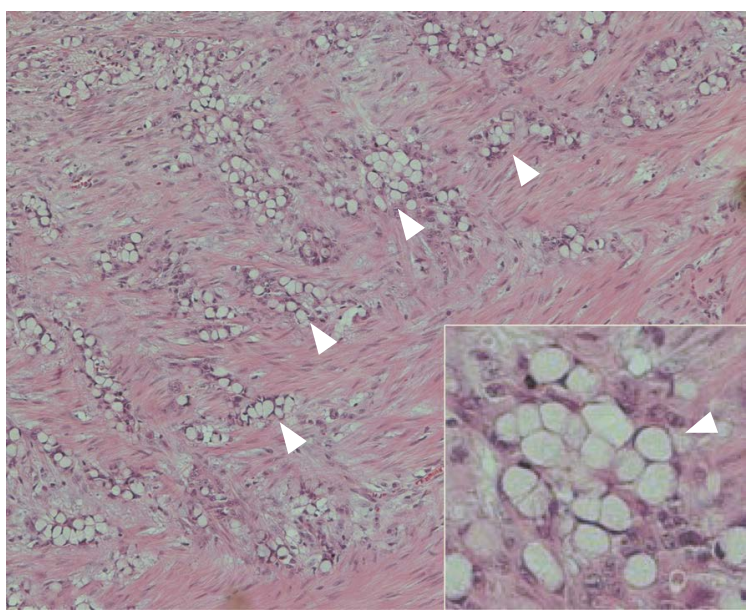

$\mathrm{F}$

Fig. 1. C. A coronal computed tomography (CT) scan of the appendix shows non-specific appendiceal wall thickening with mild periappendiceal fatty strands (arrowheads). D. An enhancing solid mass was identified in the right adnexa on an axial CT scan. E. A lowpower microphotograph shows asymmetrical concentric wall thickening of the appendix (H\&E, $\times 10)$. Tumor cells were found diffusely infiltrating the submucosal, muscle, and serosal layers. F. Under higher magnification, signet-ring cells are seen diffusely infiltrating a muscle layer of the appendix (arrowheads) (H\&E, ×100; inset, H\&E, ×400). L, lumen; M, muscle; m, mucosa; S, serosa; sm, submucosa.

non-tumorous appendicitis $[1,2]$. Our case also presented with symptoms suggestive of acute appendicitis.

Similarly to signet-ring cell carcinoma in other areas of the gastrointestinal tract, such as the stomach and colon, primary signetring cell carcinoma of the vermiform appendix has a poor prognosis $[3,9]$. The survival rate for this type of tumor in the appendix is worse than that observed for other histological types of tumors
$[3,6]$. Additionally, metastasis to adjacent organs, the regional lymph nodes, or the peritoneal cavity is common at the time of diagnosis $[4,9]$. Ovaries are the most common site of distant metastasis, as was observed in our case. Furthermore, signet ring cell carcinoma is a histopathologically distinct tumor $[6,9]$. Under microscopic examination, immature signet-ring cells permeate the wall, extensively involving the full thickness of the bowel wall. The 
involved area of the wall turns into a rigid and contracted structure with minimal mucosal alterations $[6,9]$.

For the above reasons, the preoperative detection of primary signet-ring cell carcinoma of the appendix is important for surgical planning. However, preoperative detection is invariably difficult and the correct diagnosis is usually made after surgery, because the radiologic features are non-specific and similar to those of nontumorous appendicitis.

On US, our case showed non-specific concentric appendiceal wall thickening, suggestive of acute appendicitis. Interestingly, some atypical US findings were present. These findings may be indicative of submucosal infiltrative tumors, including signetring cell carcinoma of the appendix. First, the proportion of the thickened wall area was greater than that of the true fluid-filled lumen, as distinct from non-tumorous appendicitis. Second, the submucosal and muscle layers appeared to be a single layer with a homogeneous and markedly hypoechoic echotexture (Fig. 1A). These findings were probably due to tumor cell infiltration and abundant fibrotic tissue, based on the histopathologic findings (Fig. 1E,F). We propose that such concentric areas of wall thickening are more prominent and detailed on US than CT because high-frequency sonographic images provide more information on separate bowel wall layers and better spatial resolution $[10,11]$. These US findings may overlap with those associated with infiltrative appendiceal tumors, such as lymphoma and goblet cell carcinoid tumor $[2,9]$.

In conclusion, primary signet-ring cell carcinoma of the appendix is extremely rare and its radiologic findings are non-specific. A submucosal infiltrative tumor should be included in the differential diagnosis when concentric hypoechoic submucosal thickening is noted on US, especially in clinical contexts such as potential ovarian and peritoneal metastasis.

ORCID: Young Jong Cho: http://orcid.org/0000-0003-2881-9221; Hyuk Jung Kim: http://orcid.org/0000-0002-4629-4142; Suk Ki Jang: http://orcid.org/0000-00028625-7573; Jae Woo Yeon: http://orcid.org/0000-0002-1612-6279; Ki Ho Kim: http:// orcid.org/0000-0003-0100-7936; So Ya Paik: http://orcid.org/0000-0003-4707-574X

\section{Conflict of Interest}

No potential conflict of interest relevant to this article was reported.

\section{References}

1. Pickhardt PJ, Levy AD, Rohrmann CA Jr, Kende Al. Primary neoplasms of the appendix manifesting as acute appendicitis: CT findings with pathologic comparison. Radiology 2002;224:775781.

2. Pickhardt PJ, Levy AD, Rohrmann CA Jr, Kende Al. Primary neoplasms of the appendix: radiologic spectrum of disease with pathologic correlation. Radiographics 2003;23:645-662.

3. Ruoff C, Hanna L, Zhi W, Shahzad G, Gotlieb V, Saif MW. Cancers of the appendix: review of the literatures. ISRN Oncol 2011;2011:728579.

4. Fusari M, Sorrentino N, Bottazzi EC, Del Vecchio W, Cozzolino I, Maurea $S$, et al. Primary signet ring cell carcinoma of the appendix mimicking acute appendicitis. Acta Radiol Short Rep 2012;1:arsr.2012.120017.

5. Ko YH, Jung CK, Oh SN, Kim TH, Won HS, Kang JH, et al. Primary signet ring cell carcinoma of the appendix: a rare case report and our 18-year experience. World J Gastroenterol 2008;14:5763-5768.

6. Wang HL, Dhall D. Goblet or signet ring cells: that is the question. Adv Anat Pathol 2009;16:247-254.

7. Bertuzzo VR, Coccolini F, Pinna AD. Peritoneal seeding from appendiceal carcinoma: a case report and review of the literature. World J Gastrointest Surg 2010;2:265-269.

8. Ploenes T, Borner N, Kirkpatrick CJ, Heintz A. Neuroendocrine tumour, mucinous adenocarcinoma and signet-ring cell carcinoma of the appendix: three cases and review of literature. Indian J Surg 2013;75(Suppl 1):299-302.

9. Kim HJ, Ha HK, Cho KS, Yu E, Kim JC, Yoo CS, et al. CT features of primary colorectal signet-ring cell carcinoma. J Comput Assist Tomogr 2001;25:225-230.

10. Ledermann HP, Borner N, Strunk H, Bongartz G, Zollikofer C, Stuckmann G. Bowel wall thickening on transabdominal sonography. AJR Am J Roentgenol 2000;174:107-117.

11. Maturen KE, Wasnik AP, Kamaya A, Dillman JR, Kaza RK, Pandya $A$, et al. Ultrasound imaging of bowel pathology: technique and keys to diagnosis in the acute abdomen. AJR Am J Roentgenol 2011;197:W1067-W1075. 